\title{
ANÁLISE DA INFLUÊNCIA DO PRÉ-TRATAMENTO QUÍMICO E FÍSICO SOB A CARACTERIZAÇÃO DAS FRAÇÕES CELULOSE E LIGNINA DE DIFERENTES BIOMASSAS E SEU POTENCIAL PARA PRODUÇÃO DE ETANOL DE SEGUNDA GERAÇÃO
}

\author{
Thaysi Castro Coelho Andrade* \\ Lara Neira de Siqueira** \\ Dener Alves de Souza*** \\ Fabricia Vieira Silva**** \\ Patricia Martins Guarda****** \\ Emerson Adriano Guarda ${ }^{* * * * * *}$
}

RESUMO: O desenvolvimento do etanol lignocelulósico, obtido a partir de biomassas consideradas resíduos, tem ocupado posição de destaque junto às pesquisas realizadas sobre o tema energético. Neste trabalho utilizou-se as biomassas bagaço de cana-de-açúcar, capim elefante e serragem de madeira (Angelim vermelho) para a avaliação dos teores de celulose e lignina antes e depois de serem submetidas a uma combinação de pré-tratamentos que envolvem pré-tratamento físico e pré-tratamento químico (ácido e alcalino). Desta forma pôde-se avaliar se a aplicação desses pré-tratamentos é favorável para o processo de hidrólise enzimática para geração de açúcares fermentescíveis e posterior processo de fermentação microbiana para obtenção de etanol lignocelulósico. Os resultados nos permitiram concluir que a combinação de pré-tratamentos foi mais satisfatória para promover a deslignificação, que é uma das principais barreiras encontradas para a geração do etanol lignocelulósico sendo que o teor de lignina para a cana-de-açúcar obteve redução de 46,53\% após submissão ao pré-tratamento, na serragem a redução foi de $28,45 \%$, enquanto que o capim elefante obteve melhor resultado com 62,16\% de redução. Quanto ao teor de celulose os resultados variaram em função das biomassas, para a cana-de-açúcar ocorreu uma maior disponibilidade da celulose com acréscimo de 12,21\%, para as outras duas biomassas observou-se que o pré-tratamento provocou perda de

\footnotetext{
Doutora em Biodiversidade e Biotecnologia (REDE-BIONORTE-UFT), Brasil.

E-mail: coelho.ambiental@gmail.com

** Mestre em Agroenergia pela Universidade Federal do Tocantins (UFT), Brasil.

${ }^{* * *}$ Mestre em Engenharia Ambiental pela Universidade Federal do Tocantins (UFT), Brasil.

${ }^{* * * *}$ Mestre em agroenergia e Doutoranda em biodiversidade e biotecnologia, (REDE-BIONORTE-UFT), Brasil

${ }^{* * * * *}$ Mestre em Química pela Universidade Federal de Santa Maria (UFSM). Docente assistente do Curso de engenharia de Alimentos da Fundação Universidade Federal do Tocantins, Brasil.

****** Doutorado em Química Orgânica pela Universidade Federal de Santa Maria (UFSM). Docente adjunto da Universidade Federal do Tocantins (UFT), Brasil.
} 
celulose disponível, tendo em vista que ocorreu redução no teor de $8 \%$ para o capim elefante e de $18,62 \%$ para a serragem.

PALAVRAS-CHAVE: Biomassa lignocelulósica; Celulose e lignina; Pré-tratamento.

\section{INFLUENCE IN CHEMICAL AND PHYSICAL PRE-TREATMENT WITH CELLULOSE AND LIGNIN FRACTIONS OF DIFFERENT BIOMASSES AND THEIR CAPACITY FOR SECOND GENERATION ETHANOL PRODUCTION}

ABSTRACT: The development of lignin-cellulose ethanol, derived from residual biomass, has been underscored in research on energy. Current assay comprised sugarcane bagasse, elephant grass and sawdust (red angelim) to evaluate cellulose and lignin rates prior to and after being submitted to a set of physical and chemical pre-treatments (acid and alkaline). The assay shows whether the application of pre-treatments is favorable towards the enzyme hydrolysis process for the generation of fermentable sugars and for the posterior process of microbial fermentation to obtain lignin-cellulose ethanol. Results reveal that the combination of pre-treatments was better in de-lignification which is one of the impairments for the generation of lignin-cellulose ethanol. Lignin rates for sugarcane were reduced by $46.53 \%$ after pre-treatment; in the case of sawdust, reduction reached $28.45 \%$; in the case of elephant grass, the best result was obtained with $62.16 \%$ decrease. Results on cellulose rates varied with regard to biomass: in the case of sugarcane, there was greater availability of cellulose with a $12.21 \%$ increase; in the case of the other two biomasses, pre-treatment caused a loss of available cellulose, with an $8 \%$ decrease for elephant grass and $18.62 \%$ for sawdust.

KEY WORDS: Lignin-cellulose biomass; Cellulose and lignin; Pre-treatment.

\section{INTRODUÇÃO}

O etanol obtido a partir de biomassa é considerado como uma das alternativas mais promissoras em relação aos combustíveis fósseis devido à sua queima limpa, limite de inflamabilidade mais amplo e velocidade de chamas superiores, além de poder ser misturado com gasolina ou utilizado diretamente como álcool puro 
em motores dedicados (KIM; CHOI, 2010). A celulose que compõe as biomassas é um dos principais componentes da parede celular das plantas, que tem estrutura semelhante à do polissacarídeo amido, todavia a celulose não pode ser digerida por seres humanos ou animais, o que a qualifica para a produção de bioetanol, uma vez que não concorre com os alimentos, caso do etanol obtido a partir do amido (SUN et al., 2016).

A produção de etanol celulósico, no entanto, envolve um processo muito mais oneroso do que o etanol de amido, logo a produção sustentável de etanol celulósico é um dos maiores desafios nas biorrefinarias (SUN et al., 2016). Além das dificuldades envolvendo os custos, a celulose é altamente cristalina e compacta e tal conformação estrutural, assim como sua estreita associação à lignina, hemicelulose, amido, proteínas e minerais tornam-na altamente resistente à hidrólise (ARISTIDOU; PENTTILA, 2000; GRAY et al., 2006). Justamente por essas características a produção de etanol celulósico é mais onerosa que a produção de etanol de primeira geração, pois envolve a desconstrução das fibras de celulose, lignina e hemicelulose e posterior hidrólise da celulose para obtenção de açúcares fermentescíveis.

No contraponto ao exposto a biomassa lignocelulósica é barata, renovável, existe em grande quantidade e é amigável ao meio ambiente. São esses além de outros atributos que alavancaram o desenvolvimento de extensas pesquisas sobre a produção de etanol a partir de biomassa lignocelósica nas últimas duas décadas (BEHERA et al., 2014), contribuindo de fato para que a biomassa lignocelulósica seja identificada como uma alternativa aos combustíveis a base de petróleo (TAHERZADEH, 2007).

Dentre as etapas envolvidas na fabricação do etanol lignocelulósico tem-se o pré-tratamento, que visa provocar uma desconstrução parcial na estrutura química de ligações naturais da biomassa lignocelulósica (SOKHANSANJ et al., 2005). Sendo assim, a seleção correta desse mecanismo é de suma importância no resultado final (BINOD et al., 2010), já que tal etapa se caracteriza por ser altamente onerosa (MOSIER et al., 2005). Diferentes processos com essa finalidade têm sido desenvolvidos, podendo ser classificados em químicos, físico-químicos, físicos e biológicos, além de algumas combinações entre eles.

Como cada processo de pré-tratamento tem as suas vantagens e desvanta- 
gens, algumas combinações nesses processos podem melhorar a acessibilidade das enzimas à celulose (SUN et al., 2016). O pré-tratamento pode remover parcialmente a lignina e hemicelulose, reduzir a cristalinidade da celulose e aumentar a porosidade (área de superfície acessível) da biomassa. Entre todos os métodos de pré-tratamento investigados, o químico tem sido provado ser o mais promissor (YANG; WYMAN, 2008).

\subsection{BIOMASSA LIGNOCELULÓSICA}

A biomassa lignocelulósica é classificada em quatro grandes grupos com base em sua origem: biomassa lenhosa, resíduos agrícolas (palhas de arroz/trigo/ cevada, palha de milho, bagaço de cana), culturas energéticas, e vários tipos de resíduos celulósicos (resíduos sólidos urbanos, fábrica de celulose e resíduos de serraria). Em relação à taxonomia vegetal, essas fontes são simplesmente classificadas como madeira ou espécies de árvores resinosas, ou espécies de gramíneas (KIM; LEE; KIM, 2016).

A composição química da biomassa lignocelulósica geralmente contém 35$50 \%$ de celulose, seguido de $20-35 \%$ de hemicelulose, $10-25 \%$ de lignina e uma pequena quantidade de cinzas e extrativos. Esta composição química varia em função do tipo de biomassa (SANTOS et al., 2012).

Segundo Champagne (2008), os resíduos lignocelulósicos agrícolas apresentam composição físico-química complexa, que oferece resistência ao ataque químico ou bioquímico e dificulta sua conversão mediante a hidrólise, em materiais com alto valor agregado (ZHANG et al., 2012). Essa característica da matéria-prima utilizada confere à produção de etanol lignocelulósico maiores custos que a produção de primeira geração, pois essa envolve a hidrólise das fibras de celulose e hemicelulose para obtenção de açúcares fermentescíveis, além da posterior fermentação (MARGEOT et al., 2009). 
Dentre os pré-tratamentos, o químico tem recebido mais atenção devido ao fato de os físicos serem relativamente ineficientes (RABELO et al., 2008) e os biológicos ainda não estarem prontos para uso em escala industrial, pelo menos, a curto prazo (CONDE-MEJÍA et al., 2011), no entanto uma grande quantidade de produtos químicos e de água são necessários na maioria dos pré-tratamentos químicos, que necessitam de reciclagem dos produtos químicos, eliminação da solução residual, e por vezes a alta temperatura pode resultar em elevados custos de tratamento e potencial poluição ambiental (BEHERA et al., 2014). Além disso, uma grande porção de glicose e xilose são degradadas para hidroximetilfurfural (HMF) e furfural, respectivamente, que são inibitórios aos processos microbianos (CHANDEL et al., 2011).

Visando a melhoria do rendimento dos pré-tratamentos, diversas pesquisas têm sido realizadas com intuito de se promover combinações de rotas, sendo que aquelas que combinam processos químicos e físicos são as que surtiram melhores efeitos (WONG et al., 2014).

Diante da notória característica de que o pré-tratamento é o gargalo para o desenvolvimento de bioprocessos lignocelulósicos (CHENG et al., 2008; ALVARADO et al., 2009; ZHANG et al., 2009; CONDE-MEJÍA et al., 2011), muitos produtos químicos têm sido estudados como agentes para a indústria química, entre esses os produtos alcalinos são os mais populares agentes de pré-tratamento, uma vez que são relativamente baratos e resultam em menor degradação da celulose (CARDOSO et al., 2012).

A conversão da celulose e hemicelulose biologicamente utilizando enzimas e micro-organismos requer cinco principais processos unitários: redução de tamanho, tratamento prévio para tornar as biomassas celulósicas mais propícias à ação enzimática, sacarificação enzimática para hidrolisar celulose/hemicelulose em açúcares monoméricos (açúcares fermentescíveis), fermentação microbiana para converter açúcares monoméricos em combustíveis e produtos químicos, e por fim a recuperação do produto e purificação (KIM; LEE; KIM, 2016).

Em um processo integrado de conversão de biomassa o pré-tratamento torna-se um elemento fundamental porque o desenho dos processos de fermentação e de sacarificação subsequentes dependem fortemente do resultado do pré-tratamento. Logo, o objetivo final do pré-tratamento consiste em melhorar a hidrólise 
enzimática dos hidratos de carbono (celulose e hemicelulose), consequentemente, aumentando a eficiência global de bioconversão para a produção de açúcares (KIM; LEE; KIM, 2016).

\subsubsection{Pré-tratamento físico}

O pré-tratamento físico é destinado a aumentar a área de superfície acessível específica de materiais lignocelulósicos ao ataque das enzimas, reduzindo o tamanho das partículas ou perturbando a sua regularidade estrutural. Diferentes tipos de processos físicos, tais como trituração mecânica (lascas, trituração ou moagem) e irradiação (raios gama, feixes de eletróns ou de microondas) têm sido utilizados para melhorar a digestibilidade de materiais lignocelulósicos (TAHERZADEH; KARIMI, 2008).

Dentre os processos físicos, lascar ou moer a biomassa é algo necessário para tornar o material lignocelulósico volumoso em pedaços pequenos e facilitar o processo de pré-tratamento seguinte. A moagem pode reduzir significativamente o tamanho das partículas e, consequentemente, em etapa subsequente melhorar sua hidrólise enzimática (YEH et al., 2010).

\subsubsection{Pré-tratamento químico}

\subsubsection{Pré-tratamento Alcalino}

Entre as opções de pré-tratamento já mencionados, o alcalino tem alcançado destaque, contando com uma série de características desejáveis. Os métodos alcalinos utilizam na sua maioria produtos químicos não poluentes e não corrosivos tais como amoníaco, hidróxido de sódio, carbonato de sódio, e hidróxido de cálcio, podendo ser realizado sob condições mais suaves do que os necessários para o pré-tratamento ácido. Reagentes alcalinos interagem principalmente com a lignina, tornando-se assim mais eficientes para a remoção desta (KIM; LEE; KIM, 2016; SUN et al., 2016).

As principais reações durante o pré-tratamento alcalino incluem a dissolu- 
ção da lignina e hemicelulose, além de provocar mudanças nas propriedades físicas dos sólidos tratados. Tais modificações podem envolver a área de superfície, a porosidade e a cristalinidade (KIM; LEE; KIM, 2016).

A variação do índice de cristalinidade bruta é principalmente devido à remoção de regiões amorfas (lignina e hemicelulose) da biomassa, ao invés de mudança estrutural nas fibras de celulose. Esta é a razão pela qual o índice de cristalinidade total de biomassa tratada muitas vezes aumenta após o pré-tratamento, sendo muito mais eficaz para a deslignificação de espécies de relva do que de espécies lenhosas (KIM; LEE; KIM, 2016).

Trabalhos experimentais têm reportado o uso de hidróxido de sódio ou hidróxido de cálcio no pré-tratamento de materiais lignocelulósicos e afirmam que melhora o rendimento nas próximas etapas (PARK et al., 2010).

O hidróxido de sódio é um dos métodos químicos mais estudados. Sua aplicação leva à hidratação e distensão da celulose, quebra da estrutura da lignina e redução do grau de cristalinidade, aumentando a digestibilidade dos materiais celulósicos, aliado a isso a temperatura elevada quebra a lignina e hemicelulose em fragmentos solúveis e torna a celulose mais exposta às enzimas (CARDOSO et al., 2012; HAQUE et al., 2012; MODENBACH, 2013).

\subsubsection{Pré-tratamento Ácido}

Relatos informam que a aplicação de ácidos para sacarificação de celulose já é uma prática antiga, com dados de 1819, quando já se utilizava o ácido sulfúrico concentrado para esse fim (BRACONNOT, 1819 apud HARIFARA RABEMANOLONTSOA, 2016). Depois de uma descoberta tão inicial foram avaliados vários ácidos concentrados e diluídos, além de ácidos inorgânicos e orgânicos para hidrólise (HARIFARA RABEMANOLONTSOA, 2016).

A aplicação de ácido concentrado permite a obtenção de um rendimento elevado de açúcares a partir de celulose com baixa temperatura. A taxa de hidrólise é, no entanto, mais lenta. Outras desvantagens de ácido concentrado incluem corrosão do equipamento, o alto consumo de ácido, a toxicidade para o ambiente, e o gasto de energia para a recuperação do ácido (HARIFARA RABEMANOLONTSOA, 2016).

Uma vez que as ligações glicosídicas de hemicelulose e celulose são sensíveis 
ao ácido, o pré-tratamento ácido pode ser aplicado para solubilizar hemiceluloses parciais a partir de materiais lignocelulósicos e melhorar ainda mais a acessibilidade para as enzimas de celulose. Diversos tipos de ácidos concentrados e diluídos têm sido utilizados para pré-tratar vários materiais lignocelulósicos, no entanto os que utilizam ácidos concentrados são susceptíveis a causar grave degradação da celulose, gerar alta concentração de inibidores, provocar corrosão e problemas em equipamentos, assim, os ácidos concentrados são menos atraentes (ALVIRA et al., 2010).

\subsection{COMBINAÇÃO DE PRÉ-TRATAMENTO FÍSICO E QUÍMICO}

A fim de melhorar a remoção de lignina e aumentar a eficiência do processo de hidrólise, os parâmetros físicos tais como pressão e alta temperatura podem ser adicionados ao pré-tratamento químico alcalino (HARIFARA RABEMANOLONTSOA, 2016; HAQUE et al., 2012).

A combinação de agente alcalino e alta pressão cria uma alteração físico-química na estrutura da biomassa. Esses efeitos contribuem para uma melhor acessibilidade das enzimas no caso de se aplicar a hidrólise enzimática e a melhor digestibilidade da biomassa pré-tratada, resultando em um aumento da recuperação de açúcar (HARIFARA RABEMANOLONTSOA, 2016), além do que o pré-tratamento combinado promove um reforço significativo à hidrólise enzimática (KIM; LEE; KIM, 2016). O pré-tratamento físico tem como característica aumentar a área de superfície acessível e reduzir a cristalinidade, enquanto que o pré-tratamento alcalino e ácido combinados promove a redução do teor de lignina e hemicelulose.

Logo, utilizando-se de três biomassas distintas, a saber, cana-de-açúcar (Saccharumofficinarum L.), capim elefante (Pennisetumpurpureum), e serragem de madeira angelim vermelho (Dinizia excelsa Ducke), o presente trabalho buscou realizar uma combinação de pré-tratamentos físico e químico (alcalino e ácido) de modo a identificar quais as influências desses com relação a variação no teor de celulose e lignina das biomassas, visando identificar qual das biomassas possui maior potencial para utilização na obtenção de etanol de segunda geração.

\section{MATERIAL E MÉTODOS}


A primeira etapa do trabalho consistiu em determinar o teor de lignina e celulose nas biomassas sem pré-tratamento químico, sendo elas cana-de-açúcar (Saccharumofficinarum L.), capim elefante (Pennisetumpurpureum) e farpa/serragem de angelim vermelho (Dinizia excelsa Ducke). O processo de determinação do teor de celulose e lignina foi o mesmo para as 3 biomassas, com e sem pré-tratamento.

\subsection{PRÉ-TRATAMENTO FÍSICO}

As biomassas foram desidratadas em estufa a $65^{\circ} \mathrm{C}$ até peso constante visando a remoção da umidade, trituradas em moinho de facas com peneiras de 1 $\mathrm{mm}$ de diâmetro. Posteriormente acondicionadas em sacos plásticos e mantidas em dessecador com sílica-gel até o momento das análises. Esse tipo de pré-tratamento foi dado a todas as biomassas, antes de se determinar o teor de celulose e lignina.

\subsection{DETERMINAÇÃO DO TEOR DE LIGNINA}

O teor de lignina foi estimado com adaptações com base nos procedimentos realizados por Morais; Rosa; Marconcini (2010). As análises foram realizadas em quadruplicata para cada biomassa. Após pesadas amostras de 1,0 g, moídas e secas, foram colocadas em um tubo de ensaio e adicionados $17 \mathrm{~mL}$ de ácido sulfúrico $72 \%$. Após 15 minutos de agitação vigorosa e cuidadosa, digeriu-se as amostras por $24 \mathrm{~h}$. Posteriormente adicionou-se $306 \mathrm{~mL}$ de água destilada ao almofariz para diluir o ácido sulfúrico a $4 \%$ e transferiu-se o conteúdo para um balão que foi mantido sob aquecimento e refluxo por 4 horas.

Após o refluxo as amostras foram filtradas a vácuo, sendo lavado com água destilada, sob agitação constante, para evitar perda de precipitado. O precipitado recolhido no funil foi enxaguado com água destilada até que obtivesse $\mathrm{pH}$ próximo à neutralidade. Posteriormente o funil foi levado à estufa a $105^{\circ} \mathrm{C}$ e seco até adquirir peso constante. Após secagem e estabilização na temperatura ambiente pesou-se a massa do funil somada à massa da lignina, finalmente o conjunto foi levado ao forno mufla a $550^{\circ} \mathrm{C}$ a fim de obter o teor de cinzas, conforme observado nas Equações 1 e 2 : 
Teor de Cinzas $\%=\left(\frac{\text { MFC-MF }}{\mathrm{MA}}\right) \times 100$

Teor de Lignina $\%=\left(\frac{M F L-M F}{M A} \times 100\right)-\mathrm{TC} \%$

Onde:

MF: massa do funil limpo e seco;

MA: massa da amostra;

MFL: massa do funil + lignina (após secagem em estufa);

MFC: massa do funil + cinzas (após calcinação em mufla);

TC\%: teor de cinzas.

\subsection{DETERMINAÇÃO DO TEOR DE CELULOSE}

O procedimento empregado, o qual permite quantificar o teor de celulose presente nas biomassas, se deu com base em adaptações dos trabalhos realizados por Rodrigues (2010) e Pinto; Calloni; Silva (2013). As análises foram realizadas em quadruplicata para cada biomassa. Após pesadas amostras de 1,0 g, moídas e secas, foi adicionado reagente ácido (72,73\% de ácido acético glacial, 18,18\% de água destilada e 9,09\% de ácido nítrico concentrado) em um tubo de ensaio. A mistura foi levada a banho-maria por 30 minutos para digestão. Após esse processo, adicionouse álcool etílico aos tubos. Após o resfriamento e realização da filtração a vácuo o sólido foi lavado primeiramente com etanol quente, tolueno quente e, finalmente, com éter sulfúrico quente. Em seguida, o material (amostra e papel de filtro) foi transferido para um cadinho previamente calcinado. Esse sistema foi levado à estufa a $105^{\circ} \mathrm{C}$, para secar durante 4 horas. Depois de transcorrido o tempo, o conjunto (cadinho + celulose + minerais + papel de filtro) foi pesado, e finalmente incinerado em forno mufla a $550{ }^{\circ} \mathrm{C}$. Foi possível determinar o percentual de celulose aplicando-se a Equação 3:

$$
\text { Celulose } \%=\frac{\lfloor(M i-P-M f)\rfloor x 100}{m A}
$$


Onde:

$\mathrm{Mi}=$ massa do cadinho + papel + amostra;

$\mathrm{P}=$ massa do papel de filtro (papel quantitativo);

$\mathrm{Mf}=$ massa do cadinho + cinzas;

$\mathrm{mA}=$ massa da amostra.

\subsection{PRÉ-TRATAMENTO QUÍMICo}

A metodologia aplicada para pré-tratar as biomassas foi a mesma desenvolvida por Menezes; Hennies (1991).

O material foi pré-tratado utilizando uma solução de hidróxido de sódio $(\mathrm{NaOH}) 4 \%$, em autoclave a $121^{\circ} \mathrm{C}$ por 15 minutos, nas seguintes condições de reação: $100 \mathrm{~g}$ de biomassa (base seca), com $2 \mathrm{~L}$ de solução de hidróxido de sódio a 4\%, 1:20 (m/v). O material obtido foi levado a $\mathrm{pH} 2,0$ por 30 minutos utilizando ácido fosfórico (p.a), e logo neutralizado com hidróxido de sódio.

O material foi filtrado e em seguida um volume proporcional de água destilada foi adicionado ao volume do material sólido lignocelulolítico e essa mistura foi novamente autoclavada a $121^{\circ} \mathrm{C}$ por 15 minutos, a suspensão foi filtrada e $\mathrm{o}$ material sólido desidratado na estufa a $65^{\circ} \mathrm{C}$ até massa constante, obtendo assim a biomassa seca pré-tratada.

Após o pré-tratamento químico determinou-se novamente o teor de celulose e lignina das 3 biomassas, onde foi possível constatar as modificações proporcionadas pelo pré-tratamento às biomassas quanto ao teor de celulose e lignina.

\section{RESULTADO E DISCUSSÃO}

Os resultados experimentais da composição química das biomassas lignocelulósicas que não foram submetidas ao pré-tratamento encontram-se apresentados na Tabela 1, enquanto que na Tabela 2 encontram-se os resultados da composição química após o pré-tratamento.

O percentual de lignina observado nas biomassas sem pré-tratamento se mostrou similar aos observados na literatura para todas as biomassas avaliadas, 
19-24\% para o bagaço de cana-de-açúcar (PANDEY et al., 2000), 8,26-10,9\% para o capim elefante (SANTOS; SILVA; FILHO, 2001), e 26,4-31,77\% para a serragem (MAINIERI, 1989; CASTRO, 2012).

Tabela 1. Valores médios do teor de lignina e celulose das biomassas sem pré-tratamento

\begin{tabular}{ccc}
\hline \multirow{2}{*}{$\begin{array}{c}\text { Biomassa lignoce- } \\
\text { lulósica }\end{array}$} & \multicolumn{2}{c}{ Composição (\% massa seca) } \\
\cline { 2 - 3 } Cana & Celulose & Lignina \\
Capim elefante & $53,77 \pm 1,58$ & $22,78 \pm 2,15$ \\
Serragem & $63,58 \pm 1,39$ & $12,87 \pm 1,05$ \\
\hline
\end{tabular}

Tabela 2. Valores médios do teor de lignina e celulose das biomassas após pré-tratamento

\begin{tabular}{ccc}
\hline Biomassa lignoce- & \multicolumn{2}{c}{ Composição (\% massa seca) } \\
\cline { 2 - 3 } lulósica & Celulose & Lignina \\
Cana & $60,34 \pm 4,27$ & $12,18 \pm 1,09$ \\
Capim elefante & $58,49 \pm 1,78$ & $4,87 \pm 0,35$ \\
Serragem & $55,83 \pm 2,42$ & $15,16 \pm 1,17$ \\
\hline
\end{tabular}

Os resultados apontam que as amostras submetidas ao pré-tratamento mostraram comportamentos distintos para cada biomassa analisada, conforme observado no Gráfico 1. 


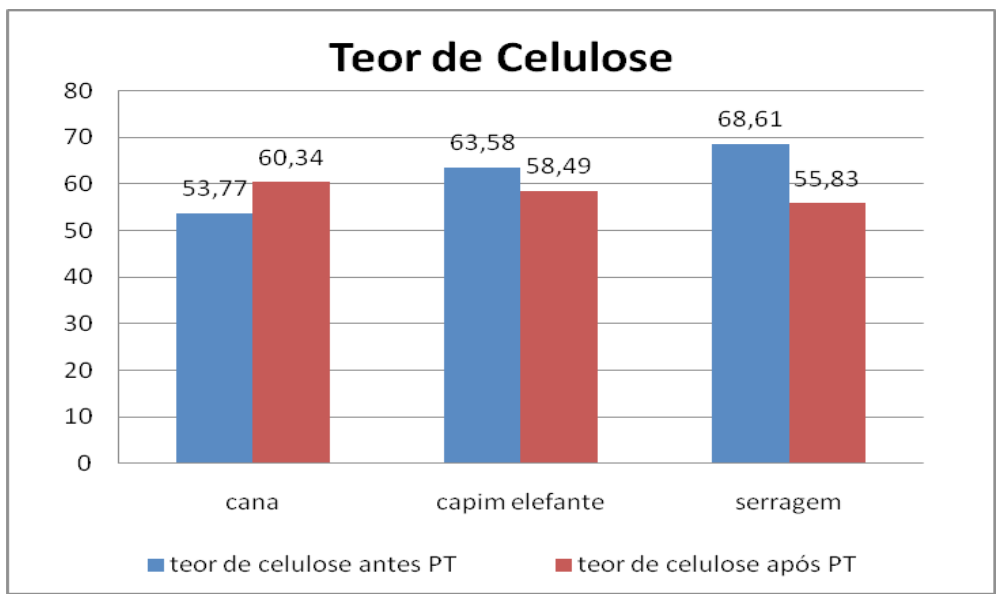

Gráfico 1. Percentual médio de celulose das biomassas

Para a cana-de-açúcar é possível observar que a disponibilidade da celulose foi 12,21\% maior após o pré-tratamento devido ao rompimento das fibras de lignina e hemicelulose na parte interna da biomassa, fato que não se repete para o capim elefante e serragem em que ocorreu redução na disponibilidade de celulose da ordem de $8 \%$ e 18,62\% respectivamente. Isto pode ser atribuído à presença de ácidos, no pré-tratamento químico, que dependendo da concentração podem causar degradação da celulose. Apesar disso sabe-se que a concentração adequada de ácido utilizada no processo auxilia os compostos alcalinos na retirada da hemicelulose e deslignificação das biomassas (ALVIRA et al., 2010). Pode-se inferir que o pré-tratamento utilizado possui maior adaptação quando aplicado à cana-de-açúcar, sendo que para o capim elefante e serragem não houve interação de maneira positiva sob a perspectiva de aumento da disponibilidade de celulose, podendo atuar de maneira contrária ao promover a degradação da celulose dessas biomassas.

No pré-tratamento alcalino parte da fração de hemicelulose foi removida, uma vez que segundo Hamelinck; Van Hooijdonk; Faaij (2005), os pré-tratamentos alcalinos são geralmente mais eficazes na solubilização de uma maior fração da lignina, deixando parte da hemicelulose insolúvel, sendo esse um dado importante caso o passo seguinte após o pré-tratamento seja a hidrólise enzimática, uma vez que favorece a reatividade da celulose, que pode ser significativamente aumentada.

A fração de lignina existente nas biomassas foi severamente afetada em função do pré-tratamento como pode ser observado no Gráfico 2. Dessa forma pode-se 
inferir que o pré-tratamento combinado (ácido e básico) foi favorável para a redução no teor de lignina podendo ser aplicado às 3 biomassas, o que representa uma vantagem, tendo em vista que a lignina se constitui como uma "barreira" que impede a eficiência da hidrólise enzimática. A redução no teor de lignina das biomassas foi da ordem de 46,53\% para a cana-de-açúcar, $28,45 \%$ para a serragem e $62,16 \%$ para o capim elefante, que obteve a maior redução no teor de lignina.

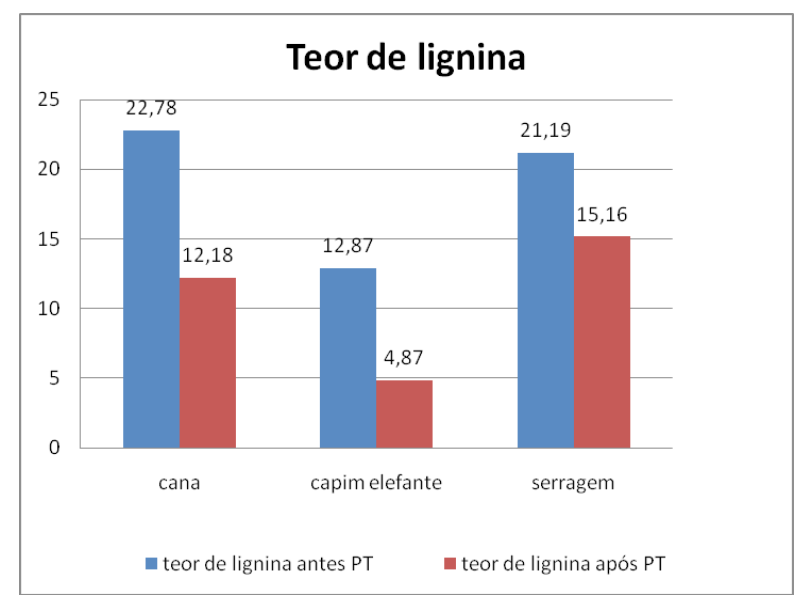

Gráfico 2. Percentual médio de lignina das biomassas

Vale ressaltar que os produtos das biomassas não foram alterados com o pré-tratamento em autoclave a $121^{\circ} \mathrm{C}$ por 20 minutos, uma vez que diversos autores afirmam que a degradação da celulose só começa a se tornar importante em temperaturas em torno de $220{ }^{\circ} \mathrm{C}$ (BOONSTRA; TJEERDSMA, 2006; LI; HENRIKSSON; GELLERSTEDT, 2005).

Os valores obtidos para o percentual do teor de celulose das biomassas se mostraram similares à faixa reportada em outros trabalhos que utilizaram biomassas como o bagaço de cana-de-açúcar, em torno de 32-45\% (PANDEY et al., 2000; ALKASRAWI et al., 2003; GONÇALVES et al., 2008; RODRIGUES et al., 2010) e serragem de madeira, em torno de 37-62\% (BARBOSA et al., 2014; MAINIERI, 1989). Para o capim elefante o valor obtido ficou superior à faixa reportada em outros trabalhos onde os valores ficam entre 30-40,7\% (LEITE; FILHO; SILVA, 2000; SANTOS, 2001). O teor de celulose e lignina aumenta com o passar do tempo de idade da planta (LEITE; FILHO; SILVA, 2000), portanto, pode-se assumir que os altos valores de celulose e 
lignina encontrados para o capim elefante se justifiquem ao fato de que as plantas de onde se fizeram o corte eram avançadas em idade.

\section{CONSIDERAÇÕES FINAIS}

O pré-tratamento se mostrou eficaz, sendo que a cana-de-açúcar apresentou melhor resultado em relação ao teor de celulose, com maior disponibilidade após o pré-tratamento, diferente das outras duas biomassas que apresentaram redução na disponibilidade de celulose após o pré-tratamento. A combinação do pré-tratamento físico e químico (alcalino e ácido) demonstrou efeito benéfico sobre a digestibilidade de materiais lignocelulósicos com intuito de facilitar o processo da hidrólise enzimática, uma vez que promoveu a redução no teor de lignina das três biomassas aliado ao aumento da disponibilidade da celulose no caso da cana-de-açúcar.

\section{REFERÊNCIAS}

ALKASRAWI, M.; ERIKSSON, T.; BÖRJESSON, J.; WINGREN, A.; GALBE, M.; TJERNEDLD, F.; ZACCHI, G. The effect of Tween-20 on simultaneous saccharification and fermentation of softwood to ethanol. Enzyme and Microbial Technology. v. 33, p. $71-78,2003$.

ALVARADO, M.; TERRA, J.; GERNAEY, K.V.; WOODLEY, J. M.; GANI, R. Biorefining: computer aided tools for sustainable design and analysis of bioethanol production. Chemical Engineering Research and Design, v. 87, p. 1171-1183, 2009.

ALVIRA, P.; TOMÁS-PEJÓ, E.; BALLESTEROS, M.; NEGRO, M. J. Pretreatment technologies for an efficient bioethanol production process based on enzymatic hydrolysis: a review. Bioresour. Technol., v. 101, p. 4851-4861, 2010.

ARISTIDOU, A.; PENTTILA, M. Metabolic engineering applications to renewable resource utilization. Curr. Opin. Biotechnol., v. 11, p. 187-198, 2000. 
BARBOSA, L. C.; PEDRAZZI, C. P.; FERREIRA, E. S.; SCHNEID, G. N.; WILLE, V. K. D. Avaliação dos resíduos de uma serraria para a produção de celulose kraft. Ciência Florestal. v. 24, n. 2, p. 491-500, 2014.

BEHERA, S.; ARORA, R.; NANDHAGOPAL, N.; KUMAR, S. Importance of chemical pretreatment for bioconversion of lignocellulosic biomass. Renewable and Sustainable Energy Reviews, v. 36, p. 91-106, 2014.

BINOD, P.; SINDHU, R.; SINGHANIA, R. R.; VIKRAM, S.; DEVI, L.; NAGALAKSHMI, S.; KURIEN, N.; SUKUMARAN, R. K.; PANDEY, A. Bioethanol production from rice straw: An overview. Bioresource Technology, v. 101, n. 13, p. 4767-4774, 2010.

BOONSTRA, M. J.; TJEERDSMA, B. Chemical analysis of heat treated softwoods. European Journal of wood and wood products, v. 64, p. 204-211, 2006.

CARDOSO, W. S.; SANTOS, F. A.; MOTA, C. M.; TARDIN, F. D.; RESENDE, S. T.; QUEIROZ, J. H. Pré-tratamentos de biomassa para produção de etanol de segunda geração. Revista Analytica, v. 56, p. 54-74, 2012.

CASTRO, J. P. Análises química e física de madeiras amazônicas visando o armazenamento de bebida destilada. Lavras, MG, 2012. Dissertação de mestrado, Universidade Federal de Lavras, Curso de Pós-Graduação em Ciência e Tecnologia da Madeira, 2012.

CHAMPAGNE, P. Bioethanol from agricultural waste residues. Environmental Progress, v. 27, p. 51-57, 2008.

CHANDEL, A. K.; CHANDRASEKHAR, G.; RADHIKA, K.; RAVINDER, R.; RAVINDRA, P. Bioconversion of pentose sugars into ethanol: a review and future directions. Biotechnol Mol Biol Rev, v. 16, p. 08-20, 2011.

CHENG, K.; CAI, B.; ZHANG, J.; LING, H.; ZHOUA, Y.; GEB, J.; XUA, J. Sugarcane bagasse hemicellulose hydrolysate for ethanol production by acid recovery process. Biochemical Engineering Journal, v. 38, p. 105-109, 2008. 
CONDE-MEJÍA, C.; JIMÉNEZ-GUTIÉRREZ, A.; EL-HALWAGI, M. A comparison of pretreatment methods for bioethanol production from lignocellulosic materials. Process Safety and Environmental Protection, doi:10.1016, j.psep.2011.08.004, p. 1-14, 2011. Disponível em: < http://www.sciencedirect.com/science/article/pii/ S0957582011000796>. Acesso em: 12 jan. 2012.

GONÇALVES, A. R.; MORIYA, R. Y.; OLIVEIRA, L. R.; SAAD, M. B. Xylanase recycling for the economical biobleaching of sugarcane bagasse and straw pulps. Enzyme and Microbial Technology, v. 43, n. 2, p. 157-163, 2008.

GRAY, K. A.; ZHAO, L.; EMPTAGE, M. Current Opinion in Chemical Biology. Bioethanol, v. 10, n. 2, p. 141-146, 2006.

HAMELINCK, C. N.; VAN HOOIJDONK, G.; FAAIJ, A. P. C. Ethanol from lignocellulosic biomass: techno-economic performance in short, middle-and long-term. Biomass and Bioenerg y, v. 28, p. 384-410, 2005.

HAQUE, M. A.; BARMAN, D. N.; KANG, T. H.; KIM, M. K.; KIM, J.; KIM, H.; YUN, H. D. Effect of dilute alkali on structural features and enzymatic hydrolysis of barley straw (Hordeumvulgare) at boiling temperature with low residence time. J. Microbiol. Biotechnol, v. 22, n. 1681-1691, 2012.

HARIFARA RABEMANOLONTSOA, S. S. Various pretreatments of lignocellulosics, Bioresource Technolog y, v. 199, p. 83-91, 2016.

KIM, H.; CHOI, B. The effect of biodiesel and bioethanol blended diesel fuel on nanoparticles and exhaust emissions from CRDI diesel engine. Renew. Energy, v. 35, p. 157-163, 2010.

KIM, J. S.; LEE, Y. Y.; KIM, T. H. A review on alkaline pretreatment technology for bioconversion of lignocellulosic biomass. Bioresource Technology, v. 199, p. 4248, 2016.

LEITE, R. M. B.; FILHO, J. L. Q.; SILVA, D. S. Produção e valor nutritivo do capim-elefante cultivar Cameroon em diferentes idades. Agropecuária técnica, v. 21, n. $1 / 2,2000$. 
LI, J.; HENRIKSSON, G.; GELLERSTEDT, G. Carbohydrate reactions during high temperature steam treatment of aspen wood. Applied Biochemistry and Biotechno$\log$, v. 125, p. 175-188, 2005.

MAINIERI, C.; CHIMELO, J. P. Fichas de características das madeiras brasileiras. Instituto de Pesquisas Tecnológicas - IPT, Divisão de Madeiras, São Paulo, 1989.

MARGEOT, A.; HAHN-HAGERDAL, B.; EDLUND, M.; SLADE, R.; MONOT, F. New improvements for lignocellulosic ethanol. Current Opinion Biotechnology, v. 20, n. 3, p. 372-380, 2009.

MENEZES, T. J. B.; HENNIES, P. T. Influência do pré-tratamento do bagaço de cana-de-açúcar com peróxido alcalino e hidróxido de sódio no sistema celulolítico de $A$. níger. Coletânea ITAL, v. 21, n. 2, p. 213-219, 1991.

MODENBACH, A. Sodium hydroxide pretreatment of corn stover and subsequent enzymatic hydrolysis: An investigation of yields, kinetic modeling and glucose recovery, Ph.D. dissertation at the University of Kentucky, 2013.

MOSIER, N.; WYMAN, C.; DALE, B.; ELANDER, R.; LEE, Y. Y.; HOLTZAPPLE, M.; LADISCH, M. Features of promising technologies for pretreatment of lignocellulosic biomass. Bioresour. Tech., v. 96, p. 673-686, 2005.

MORAIS, J. P. S.; ROSA, M. de F.; MARCONCINI, J. M. Procedimentos para análise Lignocelulósica. Documentos 236, Centro Nacional de Pesquisa do Algodão, Campina Grande-PB, 2010.

PANDEY, A.; SOCCOL, C. R.; NIGAM, P.; SOCCOL, V. T. Biotechnological potential of agroindustrial residues. I: sugarcane baggase. Bioresource Technology, v. 74, p. 69-80, 2000.

PARK, I.; KIM, I.; KANG, K.; SOHN, H.; RHEE, I.; JIN, I.; JANG, H. Cellulose ethanol production from waste newsprint by simultaneous saccharification and fermentation using Saccharomyces cerevisiae KNU5377. Process Biochemistry, v. 45, p. 487-492, 2010. 
PINTO, B.; CALLONI, G.; SILVA, S. A. da. Obtenção de acetato de celulose a partir da casca de arroz (Oryza sativa). Revista Liberato, v. 14, n. 21, p. 1-112, 2013.

RABELO, S. C.; MACIEL FILHO, R.; COSTA, A. C. A comparison between lime and alkaline hydrogen peroxide pretreatments of sugarcane bagasse for ethanol production. Applied Biochemistry and Biotechnology, v. 144, p. 87-100, 2008.

RODRIGUES, R. C. EMBRAPA - Métodos de análise bromatológica de alimentos: métodos físicos, químicos e bromatológicos. Pelotas: EMBRAPA, 2010. Disponível em: <http://www.cpact.embrapa.br/publicacoes/download/documentos/documento_306.pdf> Acesso em: 10 set. 2012.

SANTOS, E. A.; SILVA, D. S.; FILHO, J. L. Q.; Composição Química do Capim-Elefante cv. Roxo cortado em diferentes alturas. Revista Brasileira de Zootecnia, v. 30, n. 1, p. 18-23, 2001.

SANTOS, F. A.; DE QUEIRÓZ, J. H.; COLODETTE, J. L.; FERNANDES, S. A.; GUIMARÃES, V. M.; REZENDE, S. T. Potencial da palha de cana-de-açúcar para produção de etanol - revisão. Quim. Nova, v. XY, n. 00, p. 1-7, 2012.

SOKHANSANJ, S.; MANI, S.; BI, X.; ZAINI, P.; TABIL, L. G.; Binder less pelletization of biomass; ASAE annual International Meeting, Tampa Convention Centre, Tampa, Florida, July 17-20, Paper Number 056061, 2950 Niles Road, St. Joseph, MI 490859659 USA, 2005.

SUN, S.; SUN, S.; CAO, X.; SUN, R. The role of pretreatment in improving the enzymatic hydrolysis of lignocellulosic materials. Bioresource Technology, v. 199, p. 49-58, 2016.

TAHERZADEH, M. J.; KARIMI, K. Enzyme-based hydrolysis processes for ethanol from lignocellulosic materials: A review. Bio Resources, v. 2, n. 4, p. 707-738, 2007.

TAHERZADEH, M. J.; KARIMI, K. Pretreatment of lignocellulosic wastes to improve ethanol and biogas production: a review. Int. J. Mol. Sci, v. 9, p. 1621-1651, 2008. 
WONG, Y. M.; WU, T. Y.; JUAN, J. C. A review of sustainable hydrogen production using seed sludge via dark fermentation. Renew. Sustain. Energy Rev., v. 34, p. 471-482, 2014.

YANG, B.; WYMAN, C. E. Pretreatment: the key to unlocking low-cost cellulosic ethanol. Biofuels Bioproducts e Biorefining. v. 2, p. 26-40, 2008.

YEH, A. I.; HUANG, Y. C.; CHEN, S. H. Effect of particle size on the rate of enzymatic hydrolysis of cellulose. Carbohydr. Polym., v. 79, p. 192-199, 2010.

ZHANG, S.; MARÉCHAL, F.; GASSNER, M.; PÉRIN-LEVASSEUR, Z.; QI, W.; REN, Z.; YAN, Y.; FAVRAT, D. Process modeling and integration of fuel ethanol production from lignocellulosic biomass based on double acid hydrolysis. Energ y \& Fuels, v. 23, p. 1759-1765, 2009.

ZHANG, L.; LIU, Y.; NIU, X.; LIU, Y.; LIAO, W. Effects of acid and alkali treated lignocellulosic materials on cellulase/xylanase production by Trichodermareese $i$ Rut C-30 and corresponding enzymatic hydrolysis. Biomass and bioenergy, v. 37, p. 16-24, 2012.

Recebido em: 29/04/2016 Aceito em: 30/10/2017 